\title{
VOZES DOCENTES NA PERSPECTIVA DA AFETIVIDADE NA EDUCAÇÃO INFANTIL
}

\author{
VOCES DE ENSEÑANZA DESDE LA PERSPECTIVA DE LA AFECTIVIDAD EN LA \\ EDUCACIÓN INFANTIL
}

\author{
TEACHING VOICES FROM THE PERSPECTIVE OF AFFECTIVITY IN \\ CHILDHOOD EDUCATION
}

\author{
Maíra DARIDO DA CUNHA ${ }^{1}$ \\ Thais AMANCIO ${ }^{2}$ \\ Marcela BACCELLI ${ }^{3}$
}

\begin{abstract}
RESUMO: O desenvolvimento da criança na educação infantil perpassa por diversos aspectos inerentes ao contexto escolar. Considera-se, principalmente, a questão da afetividade como elemento central no processo de aprendizagem. Dessa forma, a seguinte pesquisa buscou dar voz aos docentes acerca da importância da afetividade no desenvolvimento da criança, mais especificamente, na educação infantil do município de Bertioga - SP. Para tanto, a pesquisa foi estruturada a partir de levantamento bibliográfico de acordo com os pressupostos teóricos de Wallon e Piaget, que retratam sobre a importância das interações no desenvolvimento humano, salientando também a respeito da relação entre a afetividade e a aprendizagem das crianças. Para uma conclusão fundada em experiências do contexto escolar, a pesquisa de campo foi realizada com 7 professores de diferentes escolas, por meio de uma entrevista semiestruturada com professores de escolas públicas e privadas do município de Bertioga - SP. Os dados levantados pela entrevista com docentes permitem uma reflexão mais aprofundada sobre as práticas escolares e a importância da afetividade sob a perspectiva dos docentes.
\end{abstract}

PALAVRA-CHAVE: Afetividade. Educação infantil. Professor.

RESUMEN: El desarrollo de los niños en la educación de la primera infancia implica varios aspectos inherentes al contexto escolar. Principalmente, la cuestión de la afectividad se considera un elemento central en el proceso de aprendizaje. Por lo tanto, la siguiente investigación buscó dar a los maestros una voz sobre la importancia de la afectividad en el desarrollo infantil, más especificamente, en la educación de la primera infancia en la ciudad de Bertioga - SP. Con este fin, la investigación se estructuró con base en una encuesta bibliográfica de acuerdo con los supuestos teóricos de Wallon y Piaget, que retratan la importancia de las interacciones en el desarrollo humano, destacando también la relación

${ }^{1}$ Faculdade Bertioga (FABE), Bertioga - SP - Brasil. Docente dos cursos de Graduação e Pós-Graduação. Doutora em Educação Escolar (UNESP). ORCID: https://orcid.org/0000-0002-8263-882X. E-mail: maira_darido@yahoo.com.br

${ }^{2}$ Faculdade Bertioga (FABE), Bertioga - SP - Brasil. Professora de Primeira Infância na Prefeitura de Bertioga e Escola Castelinho Infantil. Graduada em Pedagogia (FABE). Pós-Graduação em Educação Infantil e Neuropsicopedagogia (FCE). ORCID: https://orcid.org/0000-0002-0248-1747. E-mail: thaisamancio97@gmail

${ }^{3}$ Faculdade Bertioga (FABE), Bertioga - SP - Brasil. Doutoranda em Psicologia da Saúde (UMESP). Psicóloga e Professora nos cursos de Pedagogia, Direito e Administração. ORCID: https://orcid.org/0000-0001-6158-524X. E-mail: marcelabaccelli@hotmail.com 
entre la afectividad y el aprendizaje de los niños. Para una conclusión basada en experiencias en el contexto escolar, la investigación de campo se llevó a cabo con 7 maestros de diferentes escuelas, a través de una entrevista semiestructurada con maestros de escuelas públicas y privadas en la ciudad de Bertioga - SP. Los datos recopilados por la entrevista con los docentes permiten una reflexión más profunda sobre las prácticas escolares y la importancia de la afectividad desde la perspectiva de los docentes.

PALABRAS CLAVE: Afectividad. Educación Infantil. Profesor.

ABSTRACT: The development of children in early childhood education involves several aspects inherent to the school context. Mainly, the question of affectivity is considered as a central element in the learning process. Thus, the following research sought to give teachers a voice about the importance of affectivity in the child's development, more specifically, in early childhood education in the municipality of Bertioga. To this end, the research was structured based on a bibliographic survey according to the theoretical assumptions of Wallon and Piaget, which portray the importance of interactions in human development, also highlighting the relationship between affectivity and children's learning. For a conclusion based on experiences in the school context, the field research was carried out with 7 teachers from different schools, through a semi-structured interview with teachers from public and private schools in the municipality of Bertioga. The data collected by the interview with teachers allow a more indepth reflection on school practices and the importance of affectivity from the perspective of teachers.

KEYWORDS: Affectivity. Child education. Teacher.

\section{Introdução}

Indiscutivelmente, do século XIX ao século XXI, acompanhamos expressivos avanços no âmbito da atenção à Educação Infantil, que concebem a criança como sujeito de direitos.

Um dos avanços na conquista dos direitos relacionados a primeira infância, focaliza no Art. $6^{\circ}$ da Constituição Federal Brasileira, a educação como um direito fundamental de natureza social, e que o dever do Estado com a educação será efetivado mediante garantia de atendimento em creche e pré-escola às crianças de 0 a 6 anos de idade (BRASIL, 1988, art. 208).

Outro importante passo em direção ao fortalecimento da nova concepção de infância em garantia de direitos se consolida com a criação do ECA (Estatuto da Criança e do Adolescente) em 1990.

Em consequência dos avanços, a Lei de Diretrizes e Bases (LDB, 1996), Lei no 9394/96, criada para definir e regularizar o sistema de educação brasileira com bases na Constituição Federal, indica em seu art. 29, a Educação Infantil como "primeira etapa da Educação Básica, tendo como finalidade o desenvolvimento integral da criança até seis anos de idade, em seus 
aspectos físicos, psicológicos, intelectual e social, complementando a ação da família e da comunidade".

Sabe-se que o desenvolvimento da criança na educação infantil perpassa por diversos aspectos inerentes ao contexto escolar. Considera-se, principalmente, a questão da afetividade como elemento central no processo de aprendizagem infantil.

Dessa forma, a pesquisa será baseada pelos pressupostos teóricos de Piaget (1973) e Wallon (1995), que retratam sobre o desenvolvimento infantil dando ênfase na influência das emoções presentes na criança nesta faixa etária e o quanto são importantes para o seu desenvolvimento, sem considerar nenhum componente do desenvolvimento como principal, tampouco desconsiderá-los.

Assim, o presente artigo pretende discutir e evidenciar as perspectivas acerca da afetividade, dando vozes aos docentes.

Para tanto, foi realizada uma pesquisa de campo, de cunho qualitativa, sob o formato de entrevistas semiestruturadas com professores de escolas públicas e privadas. No total, foram entrevistados 7 professores cuja análise das entrevistas permitiu uma reflexão acerca da visão dos professores sobre a importância da afetividade em suas práticas na Educação Infantil.

\section{Conceitos sobre o desenvolvimento humano e a afetividade}

Para abordar a temática da afetividade no desenvolvimento da criança é preciso retratar sobre a gênese do desenvolvimento, destacando também a presença da afetividade e as suas possíveis influências no desenvolvimento e aprendizagem.

Ao longo da história, vários teóricos acentuaram a importância que a afetividade tem no desenvolvimento da pessoa, mas poucos se aprofundaram como Wallon e Piaget. Os respectivos teóricos contribuem com o trabalho, pois ressaltam a importância que a afetividade tem no desenvolvimento humano desde o nascimento até sua vida adulta.

O teórico Henri Wallon (1995) se dedicou em compreender o processo de concepção da criança, percebendo que ao estudar o seu desenvolvimento poderia entender melhor o processo e os fatores que envolve o psiquismo da pessoa, ou seja, a psicogênese. Concentrou seus estudos nas fases iniciais da criança, se aprofundando no campo da consciência, enfatizando os fatores de origem biológica e social, afirma Wallon (1995, p. 49-50):

Deste modo, na criança, opõem-se e implicam-se mutuamente fatores de origem biológica e social [...]. O objetivo assim perseguido não é mais do que a realização daquilo que o genótipo, ou gérmen do indivíduo, tinha em potência. O plano segundo o qual cada ser se desenvolve depende, portanto, 
de disposições que ele tem desde o momento de sua primeira formação. A realização desse plano é necessariamente sucessiva, mas pode não ser total e, enfim, as circunstâncias modificam-na mais ou menos. Assim, distinguiu-se do genótipo, o fenótipo, que consiste nos aspectos em que o indivíduo se manifestou ao longo da vida. A história de um ser é dominada pelo seu genótipo e constituída pelo seu fenótipo.

Wallon (1995) ressalta a influência que o contexto social tem no desenvolvimento da criança, e afirma que a realização de cada etapa do seu desenvolvimento dependerá do contexto pelo qual está inserido. $\mathrm{Na}$ dicotomia entre genótipo e fenótipo, destaca que é instável o resultado no desenvolvimento humano, pois dependem das circunstâncias sociais subjetivas vividas individualmente.

Assim, o desenvolvimento infantil é pontuado por conflitos de origem exógena e endógena (WALLON, 1995), isto é, o primeiro é o resultado da ação do indivíduo com o ambiente exterior, e o segundo, são os efeitos gerados da maturação nervosa, o ambiente interior. Todos estes processos entram em conflito em busca de equilíbrio e controle, entretanto ficam sujeitos a atividades de instabilidade em suas relações, compreendendo esses conflitos como dinamogênicos, ou seja, como estimulantes para o desenvolvimento infantil. Percebendo os conflitos no desenvolvimento da criança, destaca a importância de observar os momentos de crises.

O estudo de Wallon (1995) apresenta uma psicologia dialética, isto é, adverte que existe uma relação de determinação recíproca entre os fatores orgânicos e sociais, afirma que o homem é determinado fisiológica e socialmente. Devido a esta concepção é proposto o estudo integrado sobre o desenvolvimento do psiquismo, compreendendo assim que o ser humano é organicamente social, ou seja, não deverá desconsiderar nenhum componente do desenvolvimento como principal, tampouco desconsiderá-los, fundamenta assim a noção de quatro domínios funcionais, a psicogênese da pessoa completa: "entre os quais vai se distribuir o estudo das etapas que a criança percorre serão, portanto, os da afetividade, do ato motor, do conhecimento e da pessoa" (WALLON, 1995, p. 117). Estes domínios são chamados de "campos funcionais", que são a afetividade/emoção, o movimento, a inteligência e a pessoa. Os campos atuariam de forma integrada, suas relações nem sempre são harmônicas, muitas vezes entram em conflitos, porém são inseparáveis umas das outras.

O estágio impulsivo-emocional, é o estágio que se situa no primeiro ano de vida, onde permeiam as emoções, sendo o fator privilegiado da sua interação com o contexto que o cerca, que se nutre pelo olhar, pelo contato físico, se expressa em gestos, mímica e posturas, as suas manifestações afetivas refletem certamente na sua capacidade de agir em seu meio. "Resposta 
ao seu estado de imperícia, a predominância da afetividade orienta as primeiras reações do bebê às pessoas, às quais intermediam sua relação com o mundo físico" (GALVÃO, 1995, p. 27). As primeiras manifestações da criança são afetivas e é por meio delas que a criança se constitui em seu meio

No estágio sensório-motor e projetivo (até 3 anos), a atenção da criança se volta para o mundo físico, suas noções de movimento possibilitam mais autonomia na exploração do seu meio e na manipulação dos objetos. É neste estágio que ocorre o desenvolvimento da função simbólica e da linguagem. A expressão "projetivo" se dá pelo fato de que durante o processo do desenvolvimento o pensamento precisa do auxílio dos gestos para se exteriorizar, "o ato mental "projeta-se" em atos motores" completa (GALVÃO, 1995, p. 42). Diferente do outro estágio, a predominância que se dá são os fatores cognitivos em sua relação com meio, sendo a inteligência prática e simbólica. Todo o movimento é ação que permeia todo o desenvolvimento, separada em duas categorias, movimentos instrumentais e movimentos expressivos. O movimento instrumental é toda ação do meio físico para alcançar um objetivo específico, por exemplo, mastigar, correr ou pegar objetos.

O movimento expressivo tem uma função mais comunicativa, como exemplo seria sorrir, gesticular, chorar, entre outros, (GALVÃO, 1995). Como visto anteriormente, a partir da emoção precede a conduta cognitiva proporcionando suas relações.

A dominância do caráter afetivo em suas relações corresponde às etapas que se prestam na construção do eu, neste processo a afetividade se torna cada vez mais racionalizada, ou seja, os sentimentos começam a ser elaborados mentalmente. Para o autor, a emoção organiza a vida psíquica e encaminha à construção cognitiva, isto é, a inteligência que se expressa e se constitui por meio da linguagem e nasce das emoções.

Portanto, segundo Wallon as emoções podem inicialmente criar operações cognitivas que permitirão a construção do conhecimento, podendo também estruturar a 'pessoa' no início da vida, sem a participação da cognição. Neste aspecto a teoria de Piaget se opõe a de Wallon, ele acredita que exista relação entre afetividade e cognição, porém suas relações não são de causalidade e alternância. Afirma Piaget (1962):

É indiscutível que o afeto tem um papel essencial no funcionamento da inteligência. Sem o afeto não haveria nem interesses, nem necessidades, nem motivação; em consequência, as interrogações ou problemas não poderiam se formulados e não haveria inteligência. $\mathrm{O}$ afeto é uma condição necessária para a constituição da inteligência. No entanto, em minha opinião, não é uma condição suficiente (PIAGET, 1994, p. 129). 
Para Piaget (1994), no processo de maturação cerebral são produzidos os esquemas, que são divididos em assimilação, acomodação e equilibração. O autor define esquema como a unidade básica do comportamento inteligente, e por meio dos esquemas mentais que organizamos as experiências passadas e entendemos as futuras.

No processo de assimilação, experimentamos coisas novas com a nossa atual capacidade de entendimento (esquemas). Ou seja, incorporamos novas informações aos esquemas existentes. Por exemplo, tendo o esquema de gato, uma criança pode chamar todos os animais de quatro patas de gato. (MYERS, 2006; GROSS, 2005). Entretanto, esse processo é a capacidade de interpretar o mundo não apenas olhar o mundo, mas assimilar algumas informações, tornar seus alguns elementos do mundo. Vale ressaltar a importância que a afetividade tem neste processo para a maturação cerebral, pois Piaget acredita que a energética da conduta está relacionada a afetividade, a motivação que sustenta cada ato.

Outro conceito central é o de acomodação, que representa as estruturas mentais, ou seja, a organização que a pessoa tem de conhecer o mundo é capaz de se modificar para dar conta das singularidade do objeto, e é esta modificação que se chama acomodação (LA TAILLE, 2006).

Porém, neste processo pode-se pensar sobre a maneira de se relacionar este objeto de conhecimento, a abstração reflexiva é justamente isso, as informações que eu retiro sobre as minhas ações sobre o objeto. Afirma Taille, "Para Piaget o desenvolvimento da criança se dá a partir do pensar sobre o mundo e o pensar sobre sua ação sobre o mundo".

De acordo com Piaget (1973), o desenvolvimento cognitivo é um processo de muitas mudanças em suas estruturas, em todo o momento acontece o processo de maturação, isto é, o indivíduo constrói e reconstrói suas estruturas, o processo do desenvolvimento não é linear, mas é um desenvolvimento que se dá por saltos, rupturas, tornando-o cada vez mais apto ao equilíbrio. Denominou essas construções como estágios, que representam uma lógica da inteligência que ser superado por um estágio superior e estão intimamente relacionados ao desenvolvimento da afetividade e da socialização da criança, Piaget define os estágios em 4 períodos, sendo eles: o período sensório-motor (0 a 2 anos), o período Pré-operatório ( 2 a 7 anos), o período de operações concretas (7 a 11 ou 12 anos) e o período de operações formais (11 ou 12 anos em diante).

O período sensório-motor entende o mundo através das sensações e ações. A presença da afetividade nesse processo é muito relevante, afirma Souza (2011, p. 37), 
à evolução do período sensório-motor, o que denominou afetos perceptivos, etapa na qual a afetividade, assim como a inteligência, está ligada às necessidades fisiológicas e às 'novidades' trazidas pelo exercício da percepção. São basicamente sentimentos de agrado e desagrado, êxito e fracasso, decorrentes das ações no mundo.

Visto que a criança necessita ter oportunidades de experiências na escola que contribuam para o seu desenvolvimento, é perceptível também que a afetividade tem relação com a cognição, Piaget afirma em seus escritos:

A vida afetiva, como a vida intelectual, é uma adaptação contínua e as duas adaptações são, não somente paralelas, mas interdependentes, pois os sentimentos exprimem os interesses e os valores das ações, das quais a inteligência constitui a estrutura (PIAGET, 1990, p. 265).

A partir das perspectivas dos autores apresentados, pensamos na contribuição desses estudos para a compreensão da afetividade no desenvolvimento e aprendizagem na primeira infância. Ou seja, o desenvolvimento cognitivo interdependente das relações de afeto que serão construídas em sala de aula. Dessa forma é imprescindível que o docente tenha consciência da importância da afetividade para o processo de desenvolvimento na criança na educação infantil. Assim, torna-se fundamental investigar a visão dos docentes acerca da afetividade.

\section{Vozes docentes acerca da afetividade}

Compreender o contexto escolar de acordo com os docentes da educação infantil nos proporciona um maior contato com a realidade, e consequentemente facilitará o entendimento sobre o tema, ampliando assim as possibilidades de exercer melhor as práticas pedagógicas. Partindo desse pressuposto foi desenvolvido um estudo de caso sobre a importância da afetividade no âmbito escolar.

Os dados da pesquisa foram construídos a partir de uma entrevista previamente estruturada em questionário, com quatro perguntas dissertativas, os professores da educação infantil foram convidados a participar após apresentação da pesquisa, que foi feita pessoalmente nas escolas. A escolha dos entrevistados se deu após apresentação da pesquisa nos HTPC Hora de trabalho pedagógico coletivo das unidades escolares e desenvolvidas a partir do interesse do docente em participar. Dessa forma, a realização da entrevista foi desenvolvida em 7 diferentes escolas, 4 escolas públicas e 3 privadas no município de Bertioga - SP, com um docente de cada escola, no ano de 2019. As entrevistas foram gravadas e depois transcritas para observação e análise das respostas. 
Para caracterização das docentes, todas mulheres, foram nomeadas pelas letras $\mathrm{A}$ à $\mathrm{G}, \mathrm{e}$ caracterizadas de acordo com idade e tempo em que lecionam, conforme tabela abaixo:

Tabela1 - "Tempo em que lecionam/idade"

\begin{tabular}{|l|l|l|}
\hline Professora & $\begin{array}{l}\text { Tempo que } \\
\text { leciona }\end{array}$ & Idade \\
\hline A & 21 & 45 \\
\hline B & 5 & 30 \\
\hline C & 3 & 23 \\
\hline D & Não informou & 36 \\
\hline E & Não informou & 25 \\
\hline F & 11 & 48 \\
\hline G & 8 & 38 \\
\hline
\end{tabular}

Fonte: elaborada pelos autores.

De acordo com a tabela, o grupo de entrevistados é bastante heterogêneo. Algumas professoras estão no início de suas carreiras, outras já estão lecionando há 21 anos. As professoras $D$ e $E$ não divulgaram o tempo em que lecionam. Segundo a tabela, a idade das professoras é de 23 a 48 anos.

Quando, na primeira pergunta, questionadas se "A afetividade foi importante em sua trajetória escolar", a resposta foi unânime, 100\%, ou seja, todas as professoras alegaram que a afetividade foi importante ou muito importante em suas trajetórias escolares. Dessa forma evidencia-se a necessidade de compreender como foi esse trajeto e sob qual ótica essas docentes entendem a afetividade.

Tabela 2 - "A importância da afetividade nas trajetórias"

\begin{tabular}{|l|l|}
\hline Professor & Resposta \\
\hline A & O professor deve manter laços de afeto com seus alunos e vice-versa. \\
\hline B & $\begin{array}{l}\text { Fui uma aluna muito tímida e por isso a paciência e afetividade dos professores fazia } \\
\text { toda a diferença. }\end{array}$ \\
\hline C & Encontrei prazer em aprender com os professores em que criei certo vínculo. \\
\hline
\end{tabular}


D

$\mathbf{E}$

$\mathbf{F}$

G

É importante tratar com o amor e carinho para que as crianças possam ter esses sentimentos como referência.

Foi através da afetividade que hoje me tornei um sujeito crítico, responsável, com autoestima elevada e com valores.

É fundamental para o processo de aprendizagem.

Através do olhar afetivo podemos assimilar toda e qualquer informação.

Fonte: elaborada pelos autores.

Segundo a síntese das professoras o vínculo afetivo é de grande valia para o bom desenvolvimento na trajetória escolar, além de facilitador da aprendizagem contribuiu também para o crescimento psicoemocional. O que corrobora com o que Mendonça e Tavares (2008, p. 01) diz, que "com base na afetividade a criança desenvolve a autonomia e a inter-relação com o ambiente e com as pessoas que a envolve construindo um conhecimento global, altamente progressivo".

Tabela 3 - "O que é afetividade para você?"

\begin{tabular}{|l|l|}
\hline Professor & Resposta \\
\hline A & É respeito e se preocupar com o próximo e é impor limites quando necessário. \\
\hline B & $\begin{array}{l}\text { É um laço que criamos, baseados no carinho, respeito e confiança. } \\
\text { Ć se importar com o outro. }\end{array}$ \\
\hline D & A afetividade é uma demonstração de sentimentos e emoção de uma pessoa para outra. \\
\hline E & É a capacidade que nós temos em demonstrar nosso carinho e respeito pelo outro. \\
\hline F & $\begin{array}{l}\text { A afetividade é dar atenção ao que afeta um ser. } \\
\text { É paciência, é ter zelo e, principalmente, empatia com as crianças e todos os processos } \\
\text { de seu desenvolvimento. }\end{array}$ \\
\hline
\end{tabular}

Fonte: elaborada pelos autores.

Vê-se que algumas professoras acreditam que a afetividade está relacionada ao carinho, respeito, e demonstrar sentimentos, e outras concordam também que é a capacidade de impor limites, de se preocupar com a criança, isto é, a afetividade não está relacionada exclusivamente na definição de sentimentos, e sim na atitude de cuidado e zelo para com a criança, ressaltando assim a colocação da professora F “Afetividade é dar atenção ao que afeta um ser”.

Tabela 4 - "Para você como educador, qual a importância da afetividade no contexto escolar?

\begin{tabular}{|l|l|}
\hline Professor & Resposta \\
\hline A & $\begin{array}{l}\text { Para estreitar os laços e assim possibilitar a confiança e a garantia de um } \\
\text { processo de aprendizagem efetivo. }\end{array}$ \\
\hline B & O educando cria com o educador um laço de confiança e interesse. \\
\hline
\end{tabular}




\begin{tabular}{|l|l|}
\hline $\boldsymbol{C}$ & $\begin{array}{l}\text { A forma que o educador transmite o conhecimento pode mudar tudo. } \\
\text { D }\end{array}$ \\
$\begin{array}{l}\text { O vínculo afetivo interfere na aprendizagem, é através das interações que se } \\
\text { constrói a aprendizagem. }\end{array}$ \\
\hline $\boldsymbol{E}$ & O afeto é um laço que liga o professor e o aluno. \\
\hline $\boldsymbol{F}$ & $\begin{array}{l}\text { Para facilitar a escolarização e o processo de aprendizagem. } \\
\text { O olhar afetivo é cuidadoso e pode alertar sobre diferentes formas de } \\
\text { ensinagem, permite reflexões sobre as próprias práticas. }\end{array}$ \\
\hline
\end{tabular}

Fonte: elaborada pelos autores.

De acordo com os pressupostos teóricos, Piaget (1973) alega que sem o afeto não haveria interesses e, em consequência disso, os problemas não poderiam ser formulados, não haveria inteligência. A professora $D$ diz, "O vínculo afetivo interfere na aprendizagem, é através das interações que se constrói a aprendizagem". Ambas professoras comentaram sobre uma relação efetiva que é estabelecida entre o educando e a educadora através da afetividade. É perceptível a participação da afetividade no âmbito escolar, ainda assim de acordo com a professora $G$ "O olhar afetivo é cuidadoso e pode alertar sobre diferentes formas de ensinagem, permite reflexões sobre as próprias práticas". Ou seja, a presença da afetividade além de ser um facilitador para aprendizagem pode ser também um instrumento efetivo para a metodologia do professor.

Quadro 4 - "Você acredita que exista relação entre a afetividade e o desenvolvimento cognitivo da criança? Justifique sua resposta."

\begin{tabular}{|l|l|}
\hline Professor & Resposta \\
\hline B & $\begin{array}{l}\text { A confiança estabelecida faz com que ela consiga voltar sua concentração e } \\
\text { interesse para o conteúdo transmitido pelo educador. }\end{array}$ \\
\hline C & $\begin{array}{l}\text { Com o vínculo aprende mais. } \\
\text { A criança aprende melhor e mais depressa quando se sente amada, segura e } \\
\text { tratada com carinho. }\end{array}$ \\
\hline
\end{tabular}




\begin{tabular}{|l|l|}
\hline $\boldsymbol{E}$ & $\begin{array}{l}\text { A afetividade não se manifesta apenas com gestos de carinho físico, mas } \\
\text { também uma preparação para o desenvolvimento cognitivo, capacitando o } \\
\text { indivíduo para que se torne um sujeito crítico, autônomo e responsável. }\end{array}$ \\
\hline $\boldsymbol{F}$ & $\begin{array}{l}\text { A afetividade é um instrumento facilitador do desenvolvimento cognitivo da } \\
\text { criança. }\end{array}$ \\
\hline $\boldsymbol{G}$ & A criança que se sente amada sente vontade de aprender. \\
\hline
\end{tabular}

Fonte: elaborada pelos autores.

De acordo com as respostas, todas as professoras acreditam que exista relação entre a afetividade e o desenvolvimento cognitivo, é notório como a presença da afetividade é importante para que a cognição aconteça, isto é, a criança aprende melhor e mais depressa quando se sente amada e segura, percebendo assim que "a afetividade é um instrumento facilitador do desenvolvimento cognitivo da criança" como afirma a professora $F$. $O$ vínculo pode ajudar no desenvolvimento da criança de forma significativa, os resultados que envolvem a emoção geram mais impactos e desenvolvem melhor os aspectos cognitivos. Entretanto o professor precisa instigar o aluno de maneira afetiva para que ele possa internalizar de maneira satisfatória.

Não obstante a professora $E$ diz, "A afetividade não se manifesta apenas com gestos de carinho físico, mas também uma preparação para o desenvolvimento cognitivo, capacitando o indivíduo para que se torne um sujeito crítico, autônomo e responsável'. Visto que o afeto e a cognição andam estritamente juntos, Wallon (2007, p. 198) afirma:

É contra a natureza tratar a criança fragmentariamente. Em cada idade, ela constitui um conjunto indissociável e original. Na sucessão de suas idades, ela é um único e mesmo ser em curso de metamorfoses. Feita de contrastes e de conflitos, a sua unidade será por isso ainda mais susceptível de desenvolvimento e de novidade.

Segundo Wallon (2007), não há diferença entre corpo, cognição e afeto, são indissociáveis, e ao longo do tempo vai interferindo na vida do indivíduo de forma subjetiva, cada um com sua singularidade. É imprescindível a prática afetiva no ambiente escolar, a fim de melhorar suas relações e o desenvolvimento cognitivo e motor da criança.

\section{Considerações finais}

A pesquisa analisou a percepção de docentes acerca da importância da afetividade na educação infantil. As análises das entrevistas evidenciaram que as docentes, independentemente da idade e tempo em que lecionam, atuarem em escola pública ou 
particular, entendem como fundamental a afetividade no seu cotidiano de trabalho, ou seja, na educação infantil.

Observa-se ainda, que os mesmos docentes, apontaram a afetividade como fundamental em suas trajetórias escolares. Porém, quando perguntado sobre como definiriam a afetividade os docentes apontam sentindo no "respeito", "empatia", "cuidado", "confiança" e até mesmo a ideia de "dar limite a criança", apresentando diversas possibilidades das práticas afetivas em sala de aula.

Deste modo, a criança precisa se sentir segura na escola, há cada vez mais a necessidade de o professor levar em consideração todas as manifestações dos alunos, entendê-las de forma mais precisa, buscar novos métodos, a fim de acolher e transmitir o afeto. Esta percepção pode facilitar a prática do educador. "É necessária uma consciência do educador, de que não basta apenas educar para afetividade, é preciso educar na afetividade" (BATISTA, 2012, p. 45).

Ainda que todos os docentes vejam um impacto positivo da afetividade no desenvolvimento da criança, é preciso aprofundar as pesquisas para elucidar de que forma as práticas pedagógicas são empáticas e afetivas no cotidiano da educação infantil.

\section{REFERÊNCIAS}

BATISTA, Maria. A importância da afetividade para o desenvolvimento da criança na escola. Brasil, 2012.

BRASIL. Constituição da República Federativa do Brasil: Promulgada em 5 de outubro de 1988. Art. 205-214. Diário Oficial [da] República Federativa do Brasil, Brasília, 1988. Disponível em: http://www.planalto.gov.br/ccivil_03/constituicao/constituicao.htm. Acesso em: 05 jul. 2020

BRASIL. Lei n. 8.069, de 13 de julho de 1990. Dispõe sobre o Estatuto da Criança e do Adolescente e dá outras providências. Disponível em:

http://www.planalto.gov.br/ccivil_03/leis/L8069.htm. Acesso em: 05 jul. 2020.

BRASIL. Lei de Diretrizes de Bases da Educação Nacional (LDB). Lei Federal n. 9394/96, de 26 de dezembro de 1996. Estabelece as diretrizes e bases da educação nacional. 6. ed. Brasília: Câmara dos Deputados, Edições Câmara, 2011.

BECKER, Fernando. Abstração reflexionante: relações lógico-aritméticas e ordem das relações espaciais. A epistemologia do professor. Porto Alegre, 2012.

GALVÃO, Izabel. Uma concepção dialética do desenvolvimento infantil. Petrópolis-RJ, 1995.

GROSS, Richard. Psychology, the science of mind and behavior. 5. ed. Hodder Arnold Publication, 2005. 
MAHONEY, Abigail. Henri Wallon: Psicologia e Educação. Brasil, 2000.

MENDONÇA, Maria Alice; TAVARES, Helenice Maria. Afetividade: O fio condutor na educação infantil. Uberlândia: Faculdade Católica de Uberlândia, 12 p., 2008.

PARRAT, Silvia. Colaboradora cientifica Archives na Universidade de Genebra. Brasil, 2011.

PIAGET, Jean. La relación del afecto com la inteligência en el desarrollo mental del niño. Universidade Autónoma Metropolitana: Xochimilco. 1962.

PIAGET, Jean. A formação do símbolo na criança: imitação, jogo e sonho, imagem e representação. Rio de Janeiro: LCT, 1971.

PIAGET, Jean. O tempo e o desenvolvimento intelectual da criança. Rio de Janeiro: Forense, 1973.

PIAGET, Jean; INHELDER, Barbel. Da lógica da criança à lógica do adolescente. São Paulo, 1976.

SOUZA, Maria. As relações entre a afetividade e a inteligência no desenvolvimento psicológico. Brasília, 2011.

TAILLE, Yves. Coleção de grandes educadores. Brasil, 2006.

WADSWORTH, Barry. Inteligência e afetividade da criança. 4. ed. São Paulo: Enio Matheus Guazzelli, 1996.

WALLON, Henry. Do ato ao pensamento. França, 1942

\section{Como referenciar este artigo}

DARIDO DA CUNHA, M.; AMANCIO, T.; BACCELLI, M. Vozes docentes na perspectiva da afetividade na educação infantil. Doxa: Rev. Bras. Psico. e Educ., Araraquara, v. 22, n. 1, p. 123-136, jan./jun., 2020. e-ISSN: 2594-8385. DOI: https://doi.org/10.30715/doxa.v22i1.13914

Submetido em: 10/02/2020

Revisões requeridas em: 20/04/2020

Aceito em: 30/05/2020

Publicado em: 01/06/2020 